\title{
University of the Philippines Manila Position Statement on the Department of Health's Proposed Condom Access Program in Public High Schools
}

\author{
Hilton Y. Lam, ${ }^{1,2}$ Leonardo R. Estacio Jr., ${ }^{1,3}$ Ma. Esmeralda C. Silva, ${ }^{1,4}$ \\ Red Thaddeus DP. Miguel ${ }^{1,2}$ and Carmencita D. Padilla ${ }^{1}$ \\ ${ }^{1}$ Health Policy Hub, University of the Philippines Manila \\ ${ }^{2}$ Institute of Health Policy and Development Studies, National Institutes of Health, University of the Philippines Manila \\ ${ }^{3}$ College of Arts and Sciences, University of the Philippines Manila \\ ${ }^{4}$ Department of Health Policy and Administration, College of Public Health, University of the Philippines
}

Key Words: comprehensive sexual education, condom access program, condom distribution, public high school, sexually transmitted infections

Corresponding author: Red Thaddeus DP. Miguel Institute of Health Policy and Development Studies National Institutes of Health

University of the Philippines Manila

623 Pedro Gil Street, Ermita, Manila 1000, Philippines

Telefax: +6323543832

E-mail: red.upmanila@gmail.com

\section{INTRODUCTION}

Studies have shown that abstinence only programs are not associated with delaying the initiation of sex, hastening the return to abstinence, nor reducing the number of sexual partners. ${ }^{1}$ Consequently, abstinence only programs may not be enough to lower the risk of sexually transmitted illnesses (STIs), such as the Human Immunodeficiency Virus Acquired Immune Deficiency Syndrome (HIV AIDS).

Paradoxically, in another study, it was shown that the more strongly abstinence was emphasized by the law, the higher the average teenage pregnancy and birth rates were. ${ }^{2}$ In fact, the same study concluded that while abstinence only programs were not successful, areas that taught comprehensive sex and/or HIV education and covered abstinence along with contraception and condom access tended to be more successful, and had the lowest teen pregnancy rates. ${ }^{2}$

It is for this reason that United Nations Educational Scientific and Cultural Organization (UNESCO) has been advocating the implementation of Comprehensive Sexual Education (CSE) in high schools globally. CSE refers to an educational program that is age appropriate, developmentally appropriate, and culturally relevant to teaching about sexuality and relationships by providing information and skills development that are scientifically accurate, and realistic. ${ }^{3,4}$ Depending on the age of the adolescent student under the CSE, different lessons, such as being taught that touching is inappropriate and to report this to authorities immediately, or how to make healthy respectful relationship choices, are being delivered. To integrate this to the Department of Education (DepEd) curriculum would mean including the following topics into the education of public school students throughout 
their primary and secondary schooling: Human Body and Development, Values and Attitudes Towards Others and Social Skills, Healthy Relationships, Fidelity, Sexuality and Sexual Behaviors, Sexual and Reproductive Health, Sexually Transmitted Infections, Personal Safety, Gender, Media, and Human Rights.

In line with these modules, schools would be expected to teach cognitive skills on reproductive health, specifically early and teen pregnancy, healthy parental practices, and benefits and risks of different contraceptive methods, including abstinence and use of condoms for the older teenagers. Life skills would also be taught alongside, including critical assessments of information and services.

Along the lines of these recommendations and acting on their duty to lower the incidence of STIs in the country, news banners have previously recounted the stand of the Department of Health in distributing condoms to students despite strong opposition from the Catholic Church, advocates, and influential personalities. As stated in the news media platforms, the Department of Health was said to allocate $\mathrm{PhP} 50$ to $\mathrm{PhP} 100$ million to target the distribution of 9 million condoms to health centers and schools for students aged 15-24 years old, beginning June of $2017 .^{5}$

This declaration has led to DepEd announcing that they forbid the distribution of condoms in schools, neither do they allow them to be available to students within public schools. They instead refer students to local health centers in order to procure condoms.

A second hurdle facing students who wish to access condoms from the rural health units (RHUs) and government hospitals is Republic Act No. 10354, otherwise known as the Reproductive Health Law. Under this law, "No person shall be denied information and access to family planning services, whether natural or artificial: Provided, That minors will not be allowed access to modern methods of family planning without written consent from their parents or guardian/s except when the minor is already a parent or has had a miscarriage." According to the National Youth Commission, this is problematic, as the Filipino youth are not open to their parents about sexual practices, and there is a social stigma associated with teenage sexual activity in our country. Thus, the youth are reluctant to approach their parents for consent, and consequently opt not to get condoms.

The University of the Philippines Manila (UP Manila) recognizes the importance of condom use to prevent the spread, and reverse the trends of HIV, and other STIs. As a unified body we concur with studies manifesting that the use of condoms lowers HIV seroconversion and averts risks of diseases transmitted through genital secretions, genital ulcer diseases, and other sexually transmitted diseases. ${ }^{7,8}$

In the context of the Filipino youth, within the ages of 15 to 24 years old, there has been an increasing prevalence of premarital sex, and the gap between the sexes is consistently narrowing. ${ }^{9}$ In the 2013 Young Adult Fertility and Sexuality Study, 21\% of high school students admit to having premarital sexual activities, and this prevalence increases to $44 \%$ by the time they graduate from high school. Among the youth that had premarital sexual experience, $63 \%$ did not use any protection. ${ }^{9}$ This lack of use of protective material has manifested through other studies that show that Filipino teenagers 15 to 17 years old who have sex with men are exposed to the same risk as adults, ${ }^{10}$ and therefore it is to no surprise that majority of new HIV infections occur among 15 to 24 years old. ${ }^{11}$ Due to this reality, aligned with the Lancet Commission on Adolescent Health and Wellbeing, UP Manila supports condom access to public high school students. Therefore, UP Manila recommends the following:

1. Develop and promote CSE programs that are evidencebased, locally appraised, context driven, culturally sensitive, and age appropriate. To promote HIV/AIDS/ STI prevention programs, it is essential that strategies must address health skills that teenagers can bring with them into adulthood. ${ }^{12}$ These programs should incorporate mechanisms that will ensure long-term sustainability.

2. It is imperative to provide counseling to students who are contemplating accessing condoms, as studies have shown that accessing condoms without counseling increased teen fertility by $10 \%$ compared to areas where these are provided with counseling. ${ }^{13}$ Likewise, teachers and counselors must be properly educated and equipped to take up this challenge.

3. The Implementing Rules and Regulations of Republic Act No.10354 should be amended. Specifically the statement, "...minors will not be allowed access to modern methods of family planning without written consent from their parents or guardian/s except when the minor is already a parent or has had a miscarriage," should be re-phrased to, "... minors will not be allowed access to modern methods of family planning without written consent from their parents or guardians including school counselors, except when the minor is already a parent or has had a miscarriage."

4. Culturally sensitive sexuality education should begin at home. It is vital therefore to capacitate parents and families in sexuality education. In order to help children, make better sexual choices, parents should be encouraged to talk more with their children about sexuality, particularly in aspects related to feelings and emotions. ${ }^{14}$ Therefore, there should be modules in the CSE that include parents or guardians.

5. Strengthening the relationship between the school and the local government would create an avenue for a community-based approach, wherein students acquire reproductive health information, services, and methods not just in the school, but also in their community, including the RHUs, hospitals, medical clinics, teen health kiosks where available, and civil society 
organizations that run programs for adolescents. $\mathrm{DOH}$ may also link together with the Department of Social Welfare and Development to provide community-based youth centers.

6. The DOH, DepEd, and other concerned agencies and stakeholders must jointly be involved in the process of developing and implementing the guidelines of these programs. These strides must incorporate key stakeholders to voice the opinions of the youth, such as the National Youth Commission. Other stakeholders such as, the Population Commission, must also be involved in these undertakings.

7. The DOH and the Department of Science and Technology should collaborate on internet-based programs that increase awareness of proper condom use and to eradicate the stigma of condom use among the youth, such as positive online counseling, and Internet information dissemination.

8. Finally, throughout this endeavor, we must always safeguard the safety and wellbeing of students with the help of their parents and teachers.

\section{Acknowledgement}

The authors benefitted from the round table discussion with stakeholders on the DOH Proposed Condom Access Program in Public High Schools entitled "Beyond Latex, Glow-in-the-dark, Flavored, or Calypso: A Round Table Discussion on Adolescent Sexuality \& the Condom Access Program" held on March 1, 2017 in UP Manila.

\section{Statement of Authorship}

All authors have approved the final version submitted.

\section{Author Disclosure}

All the authors declared no conflict of interest.

\section{Funding source}

No external funding.

\section{REFERENCES}

1. Kirby D. Emerging answers: research findings on programs to reduce teen pregnancy and sexually transmitted diseases. The National Campaign to Prevent Teen and Unplanned Pregnancy [Online]. 2007 [cited March 7, 2017]. Available from https://ppt-elect.centerschool. org/providers/304/emergingsumm.pdf.

2. Stranger-Hall K, Hall D. Abstinence-only education and teen pregnancy rates: why we need comprehensive sex education in the U.S. PLoS One. 2011; 6(10): e24658. DOI: 10.1371/journal.pone.0024658.

3. UNESCO. International technical guidance on sexuality education: an evidence-informed approach for schools, teachers and health educators. Paris, UNESCO; 2009. p. 2.

4. UNESCO. Comprehensive sexual education: a global review. Paris, UNESCO; 2015. p. 4.

5. Torres, SA. DOH firm on plan to distribute condoms to students. ABS-CBN News [Online]. December 28, 2016 [cited April 3, 2017]. Available from http://news.abs-cbn.com/news/12/28/16/doh-firmon-plan-to-distribute-condoms-to-students.

6. Republic of the Philippines. An act providing for a national policy on responsible parenthood and reproductive health of 2012. Republic Act No. 10354; July 23, 2012.

7. Weller S, Davis-Beaty K. Condom effectiveness in reducing heterosexual HIV transmission. The Cochrane Library. Issue 1. Art. No.: CD003255. DOI: 10.1002/14651858.CD003255.

8. Swiss AIDS Federation. Advice manual: doing without condoms during potent ART. Swiss AIDS Federation, 2008.

9. Demographic Research and Development Foundation (DRDF) and University of the Philippines Population Institute (UPPI). 2013 YAFS4 key findings. Quezon City: DRDF and UPPI [Online]; 2014 [cited March 7, 2017]. Available from https://www.drdf.org.ph/yafs4/ key_findings.

10. Department of Health - Epidemiology Bureau. Integrated HIV behavioral and serological surveillance fact sheet. Department of Health Epidemiology Bureau [Online]; 2016[cited March 7, 2017] Available from http://www.doh.gov.ph/sites/default/files/publications/ serials_2015\%20Integrated\%20HIV\%20Behavioral\%20Serologic\%20 Surveillance\%20Fact\%20Sheets.pdf.

11. UNAIDS. Press release: UNAIDS report indicates new HIV infections in the Philippines have doubled in the past 6 years. UNAIDS [Online]; 2016 [cited March 7, 2017]. Available from https://unaids-ap. org/2017/08/01/press-statement-unaids-report-indicates-new-hivinfections-in-the-philippines-have-doubled-in-the-past-6-years/.

12. Patton G, Sawyer S, Santelli J, et al. Our Future: a Lancet Commission report on adolescent health and wellbeing. The Lancet Commissions; 11 June 2016 387(10036):2423-78. DOI:10.1016/S0140-6736(16) 00579-1.

13. Lucea M, Hindin, M, Gultiano S, Kub J, Rose L. The context of condom use among young adults in the Philippines: implications for HIV prevention. Health Care Women International; 2013 34(3-4): 22-48.

14. Buckles, S, Hungerman D. The incidental fertility effects of school condom distribution programs. National Bureau of Economic Research Papers [Online]; 2016 [cited March 7, 2017]. Available from http:// www.nber.org/papers/w22322.pdf. 